\title{
NUMERICAL SIMULATION OF LATERAL CONTROL JETS OF AN INTERCEPTOR MISSILE
}

\author{
Sumit Krishnan $^{1}$, A.K. Jouhari ${ }^{2}$, R. Balu ${ }^{3}$ \\ ${ }^{\text {I} A s s i s t a n t ~ P r o f e s s o r, ~ A e r o s p a c e ~ E n g i n e e r i n g, ~ A S E T, ~ A m i t y ~ U n i v e r s i t y ~(L u c k n o w ~ C a m p u s) ~ U P, ~ I n d i a ~}$ \\ ${ }^{2}$ Professor, ASET, Amity University (Lucknow Campus) UP, India \\ ${ }^{3}$ Ex-Group Director at VSSC, ISRO, Thiruvananthapuram \& Professor, Noorul Islam University, K.K. Dist., India
}

\begin{abstract}
The interceptor missile is an anti-ballistic missile designed to counter the ballistic missiles like Intermediate Range Ballistic Missiles and Intercontinental Ballistic Missiles launched from any country. These missiles use side jets from their surface in order to target towards the ballistic missiles. The analysis of this side jet in the presence of free stream flow and its impact on the missile itself is of great importance. Since the jet comprises of chemically reactive species, it is essential to know the amount of attenuation of the radio signals passing through them. In the past few years many experiments and theoretical studies have been carried out to characterize the jet-atmosphere interaction in wind tunnel but it is difficult to scale these results to flight conditions because of free stream/plume chemistry, Reynolds number, surface, and wall interference effects. Therefore, it is necessary for computational studies to supplement the experimental efforts and explore the physics involved to obtain the performance characteristics and flow field structure of jet/atmospheric interaction. The objective of the present study is to simulate this lateral control jet and its effect due to presence of main free stream flow. The spherically blunted ogive shaped cylindrical body is used here as a typical shape representing the interceptor missile. The simulation is done using the CFD software package AnsysFluent (V15) at the given conditions of altitude $30 \mathrm{~km}$ and Mach 3, with and without jet \& finally the results are compared.
\end{abstract}

Keywords: Interceptor Missile, RCS (Reaction Control System), Lateral Jet, Supersonic-flow, Free-stream, Plume, Aerodynamics, Computational Fluid Dynamics (CFD)

\section{NOMENCLATURE}

$\mathrm{M}=$ Mach number

$\mathrm{C}_{\mathrm{m}}=$ Moment coefficient (pitching)

$\mathrm{C}_{\mathrm{d}}=$ Drag coefficient

A=Angle of attack

$\mathrm{P}=$ Pressure

$\mathrm{T}=$ Temperature

$\rho_{=\text {Density }}$

\section{INTRODUCTION}

Interceptor missile stands opposite to ballistic missiles in the field of their functioning and applications. To perform quick maneuvers during flight, these missiles use divert and attitude reaction control systems (RCS). The use of such system has been proved to be more effective than the conventional lifting control surfaces as used by ballistic missiles for maneuvering. The RCS thruster provides a side jet which comes out at very high speed from the surface of the missile. The ejection of jet provides a reactionary force to the body which later results into a moment about centre of gravity for maneuvering. This enables the missile to intercept the fast moving ballistic missiles. When the jet interacts with the main free stream flow, it results into a highly complicated flow-field characterized by shock-shock interaction and shock-boundary layer interaction. Many experiments in past decades has been made in the wind tunnel but as its difficult to facilitate the real flight conditions, very fewer information is available regarding jet-atmospheric interaction. The lateral jet direction and reactionary force over missile is shown in figure 1.

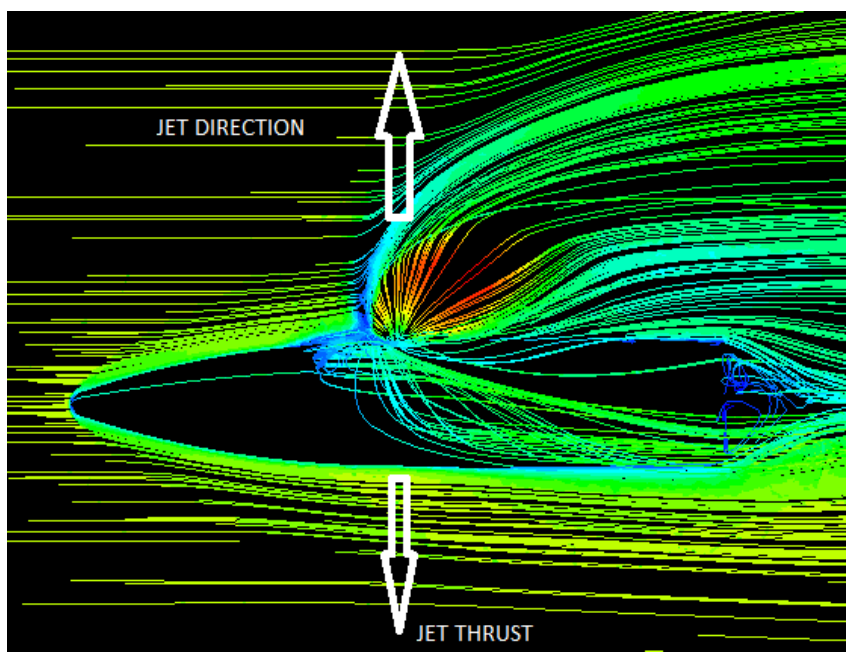

Fig -1: Interceptor missile with a lateral jet

The main advantage of using side jet control system over conventional system of lifting control surfaces is that they 
never lose their ability of controlling the body even at low dynamic pressure and high altitude flight conditions. Furthermore, they provide quick and better control for maneuvering (pitching, yawing and rolling). A Problem of stalling is one of the major drawbacks associated with lifting control surfaces while lateral control jet system is free from these limitations.

\section{MISSILE CONFIGURATION CONSIDERED}

A small interceptor missile is modeled as a spherically blunted ogive shaped cylindrical body. The lateral jet thruster is positioned on the cylinder immediately following the ogive curve-cylinder junction. The Fortran program was written on Linux platform in order to generate the coordinates of ogive curvature. A schematic of the flow geometry used to study the jet-atmospheric interaction with a lateral jet is shown in figure 2. The diameter of the lateral jet is $25.016 \mathrm{~mm}$. Zero angle of attack was considered for the current numerical simulation.

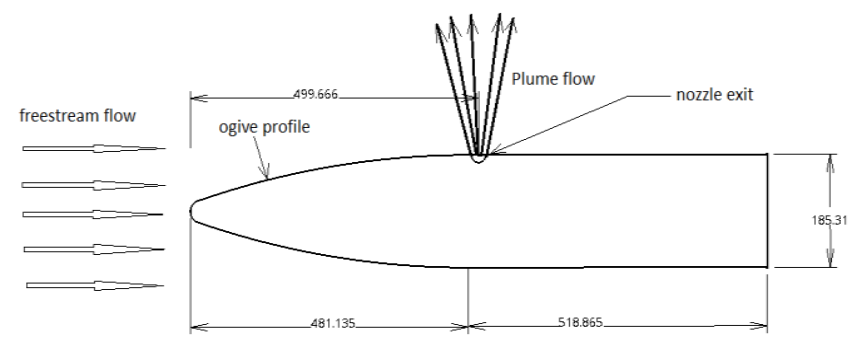

Fig -2: Schematic view of the flow (All dimensions are in $\mathrm{mm}$ )

\section{PREPROCESSING-GRID GENERATION}

In order to analyze the flow, the three dimensional geometry enclosed within a computational fluid domain was first drawn in the design modeler of Ansys and then unstructured mesh were created using the meshing module of the software suite. The fluid domain created around the missile body can be seen in figure 3 .

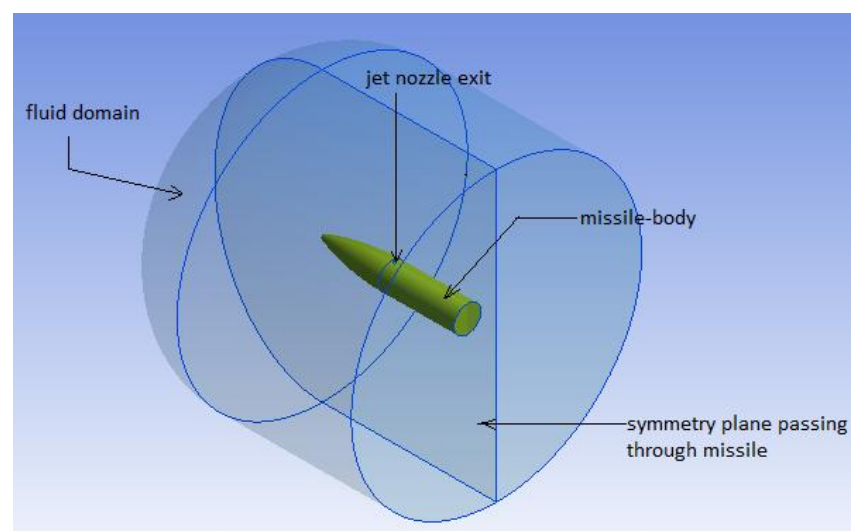

Fig -3: Isometric view of the fluid domain around missile body

The dimensions of the domain considered here is in such a way so that the outer boundaries may not interfere with the lateral jet flow as well as the flow around the body. Tetrahedral cell elements were used in the entire domain.
Very fine grid elements are placed in the regions near the jet exit and the nose of the vehicle to resolve the larger gradients in flow variables. Inflation layers were used to capture the boundary layer effects near surface of the body.

\section{BASIC FLUID FLOW GOVERNING EQUATIONS}

Fluent's solver solves the governing equations for the conservation of mass, momentum and energy of fluid flow for the given model. Control-volume-based technique is used that consists of:

- Division of the domain into discrete control volumes using a computational grid.

- Integration of the governing equations on the individual control volumes to construct algebraic equations for the discrete dependent variables ("unknowns") such as velocities, pressure, temperature, and conserved scalars.

- Linearization of the discretized equations and solution of the resultant linear equation system to yield updated values of the dependent variables.

The governing equations used are as follows:

1) Equation for conservation of mass

$\frac{\partial \rho}{\partial t}+\nabla \cdot(\rho V)=0$

2) Equations for conservation of momentum

a) $x$ momentum equation

$$
\frac{\partial(\rho u)}{\partial t}+\nabla \cdot(\rho u V)=-\frac{\partial p}{\partial x}+\rho f_{x}+\left(F_{x}\right)_{\text {viscous }}
$$

b) y momentum equation

$$
\frac{\partial(\rho v)}{\partial t}+\nabla \cdot(\rho v V)=-\frac{\partial p}{\partial y}+\rho f_{y}+\left(F_{y}\right)_{\text {viscous }}
$$

c) $\mathrm{z}$ momentum equation

$$
\frac{\partial(\rho w)}{\partial t}+\nabla \cdot(\rho w V)=-\frac{\partial p}{\partial z}+\rho f_{z}+\left(F_{z}\right)_{\text {viscous }}
$$

3) Equation for conservation of energy

$$
\begin{array}{r}
\frac{\partial}{\partial t}\left[\rho\left(e+\frac{V^{2}}{2}\right)\right]+\nabla \cdot\left[\rho\left(e+\frac{V^{2}}{2}\right) V\right]=\rho \dot{q}-\nabla \cdot(p V)+ \\
\rho(f \cdot V)+\phi_{\text {viscous }}^{v}+W_{\text {viscous }}^{v}
\end{array}
$$

These three equations involve four dependent variables, $P$, $\mathrm{p}, \mathbf{V}$, and e. A fourth equation is obtained from a thermodynamic state relation for e. If the gas is assumed to be calorically perfect, then

$e=c_{\mathrm{v}} T$

where, ${ }^{C_{V}}$ is the specific heat at constant volume.

The system of equation is completed by using perfect gas equation of state,

$p=\rho R T$ 


\section{FLOW SOLVER DESCRIPTION}

A CFD software AnsysFluent is used for the simulation. The pressure-based coupled solver is a good alternative to Fluent's density-based solvers when dealing with applications involving high-speed aerodynamics with shocks. Selection of the coupled algorithm was made in the Solution Methods panel. Here, low altitude of 30 kilometres, neglected effect of turbulence, compressible supersonic laminar flow is assumed. Computational studies were carried out to determine the aerodynamic coefficients and flow-field structure on the selected missile model.

\section{BOUNDARY CONDITIONS}

To model free-stream conditions, the inlet to the fluid domain has been set to the far-field boundary condition while the pressure-outlet boundary condition is used at the outlet of the fluid domain. The lateral jet at turned off condition is given a boundary of no-slip wall. This condition is referred as jet-off condition. The surface wall of the missile body is also given a condition of no-slip wall. Symmetry boundary condition is employed to the symmetry plane of the computational domain passing through the missile body. Mass flow-inlet boundary condition is used for jet-on case to eject the fluid with a given mass flow rate and exit pressure of $0.149858 \mathrm{~kg} / \mathrm{sec}$ and $1.833 \mathrm{e} 5 \mathrm{pa}$ respectively. The main free-stream and jet properties along with the operating conditions used for the simulation are shown in Table 1 and Table 2. A zero angle of attack is assumed for the simulation, that is, the free-stream direction coincides with the missile axis.

Table -1: Air and Jet Properties

\begin{tabular}{|c|c|c|}
\hline Properties & Free-stream air & Jet \\
\hline $\mathrm{c}_{\mathrm{p}}$ & $1006.43 \mathrm{~J} / \mathrm{kg}-\mathrm{K}$ & $2126 \mathrm{~J} / \mathrm{kg}-\mathrm{K}$ \\
\hline $\mathrm{k}$ & $0.0242 \mathrm{w} / \mathrm{m}-\mathrm{k}$ & $0.028701 \mathrm{w} / \mathrm{m}-\mathrm{k}$ \\
\hline$\mu$ & $1.475 \mathrm{e}-5 \mathrm{pa}-\mathrm{sec}$ & $6.75 \mathrm{e}-6 \mathrm{pa}-\mathrm{sec}$ \\
\hline$\gamma$ & 1.4 & 1.2 \\
\hline Mol. wt & 28.966 & 21.02 \\
\hline
\end{tabular}

Table -2: Flow Conditions

\begin{tabular}{|c|c|c|}
\hline $\begin{array}{c}\text { Operating } \\
\text { conditions }\end{array}$ & Free-stream air & Jet \\
\hline Mach number & 3 & 2.446 \\
\hline $\begin{array}{c}\text { Total } \\
\text { Temperature }\end{array}$ & $634 \mathrm{~K}$ & $2943 \mathrm{~K}$ \\
\hline Pressure & $1.197 \mathrm{e} 3 \mathrm{pa}$ & $1.833 \mathrm{e} 5 \mathrm{pa}$ \\
\hline
\end{tabular}

\section{RESULTS AND DISCUSSION}

The simulation is done for both Jet-off and Jet-on conditions. The interaction of side-jet with the main freestream had resulted into a highly complicated flow around the missile body. The features of this flow-field structure can be visualized through a graphic ability of Fluent to show contours, vectors and streamlines in terms of magnitude of Mach number. The simulation has also been carried out for the jet alone (in the absence of free-stream flow) to understand the jet flow-field. The contours of Mach number for jet in the absence of external flow can be seen in figure 4. As the jet expands from the nozzle orifice, it spreads outside in a shape resembling a feather or a plume. The variations in a velocity magnitude can be sensed through Mach contours. The expansion fan, which is a continuous expansion region near the lip of the orifice can be visualized as an infinite number of Mach waves as shown by the figure. Contours of Mach number for jet-off and jet-on conditions in the pitching plane are shown in figure 5(a) and 5(b).

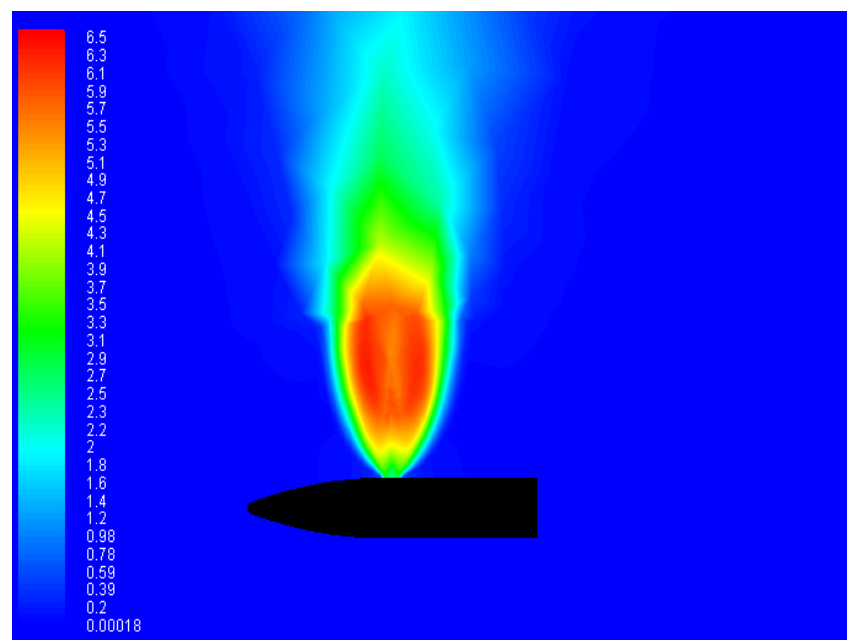

Fig -4: Contours of Mach number for lateral jet with no free-stream flow

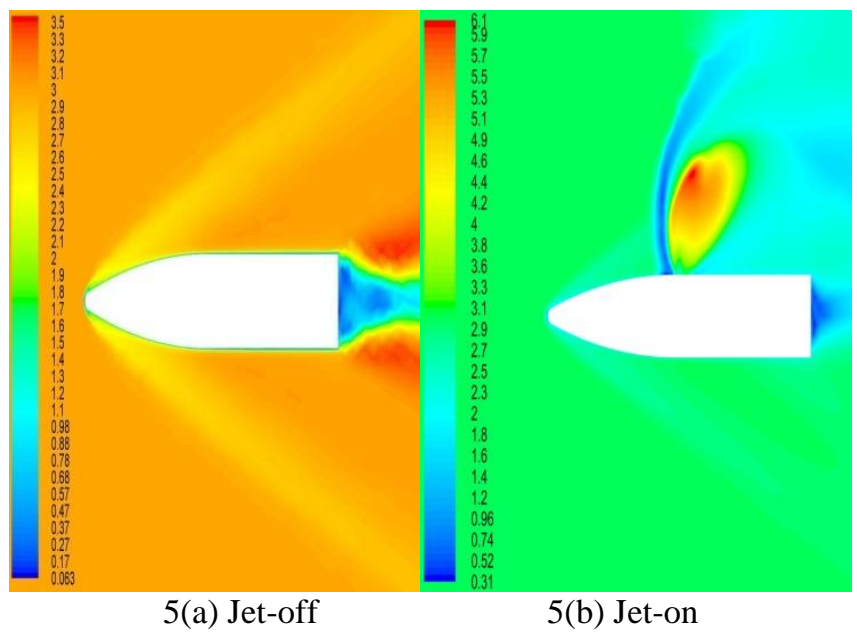

Fig -5: Contours of Mach number for Jet-off and Jet-on

Figure 5(a) shows the picture of a detached bow shock wave which stands in front of a blunt body in a supersonic flow. It is an almost explosive compression process where the pressure increases almost discontinuously across the wave. When the figure is examined closely, qualitative changes across the wave are noted. Mach number and velocity of the free-stream are shown to be decreased but remains supersonic behind the oblique shock wave. Mach contours for jet-on condition can be seen in figure 5(b) for 
comparison. The side-jet coming out from the nozzle exit acts like a body obstructing the main free-stream flow and forcing it to deflect in lateral and transverse directions.

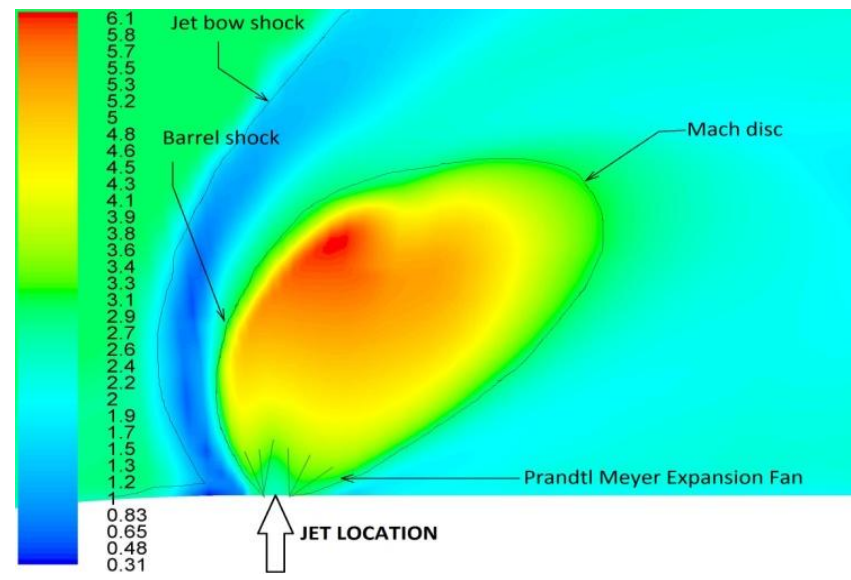

Fig -6: Zoomed view of the region of jet free-stream interaction

Figure 6 shows the zoomed view where jet-atmospheric interaction had resulted into the generation of three dimensional shockwave known as jet bow shock. The jet expands through Prandtl Meyer fan at the lip of the nozzle exit into the jet plume enclosed within barrel shock and Mach disc. Mach disc acts as a normal shock that slows down the high speed ejecting fluid from the orifice. Velocity of the mainstream has found to be decreased to a very low value in a region just behind the jet bow shock.

Velocity vectors colored by Mach number for jet-off condition are shown in figure 7.

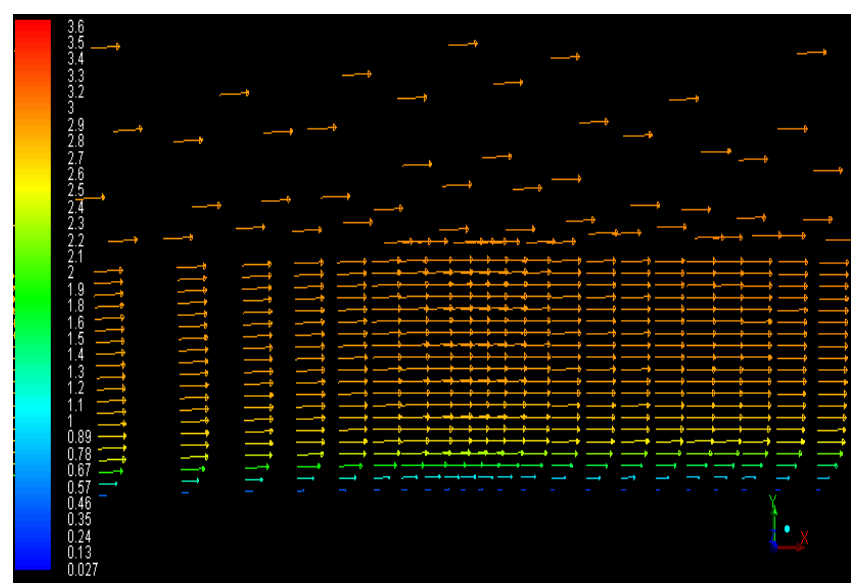

Fig -7: Velocity vectors colored by Mach number near jet location at jet-off condition

Velocity can be seen to be varying from zero value adjacent to the surface to the maximum free stream value at the outer edge of the boundary layer. No slip wall condition due to presence of viscous effects is clearly visible. Figure 8 shows the velocity vectors colored by Mach number for jet-on condition.

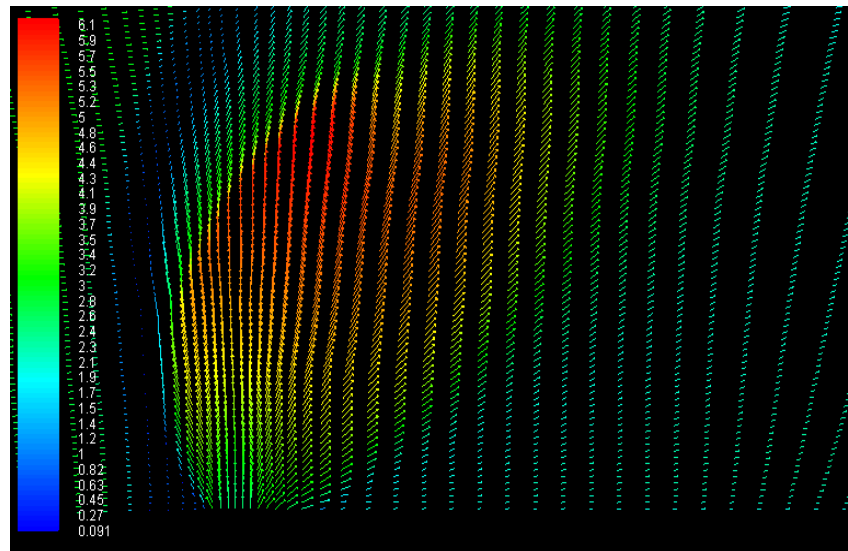

Fig -8: Velocity vectors colored by Mach number near jet location at jet-on condition

Velocity vectors for jet on case, shows the abrupt change in their direction of motion. The vectors of free stream can be seen to be deflected in different directions. This is because of the obstruction caused by three dimensional nature of the side jet.

Streamlines as noted from figure 9(a) and (b) for jet-off case are passing very smoothly and following the shape of the body as their path of motion, while the case when the jet is on as shown by figure 10 (a) and (b) stands in contrast to the jet-off case. It gives a clear image revealing the flow separation. It can be deduced from the figure 10 that streamlines do not follow the body shape if the jet is on and experience a force from the jet which as a result tends the body itself into a new path for motion.

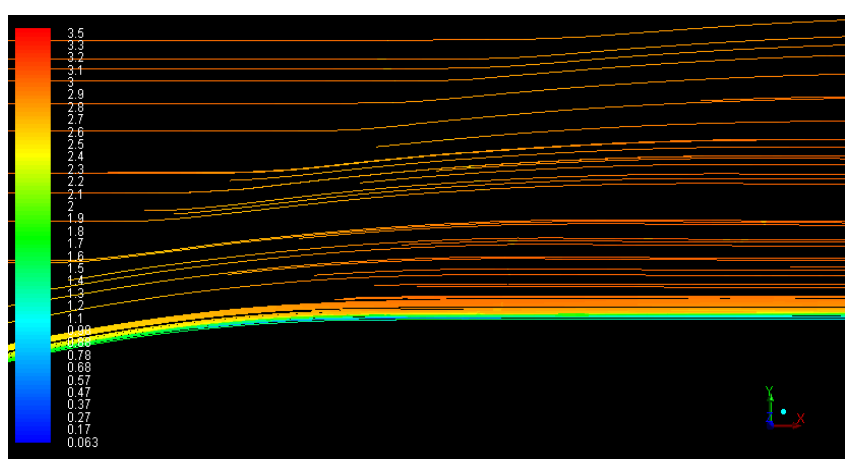

Fig -9 (a): Streamlines colored by Mach number for jet-off condition

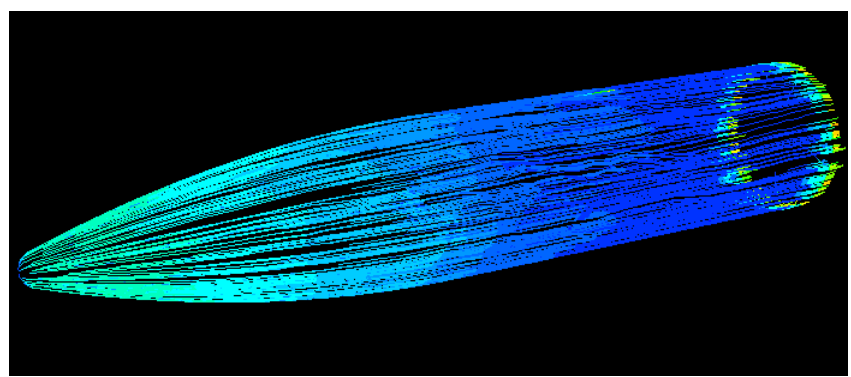

Fig -9(b): Streamlines following the shape of the missilebody 


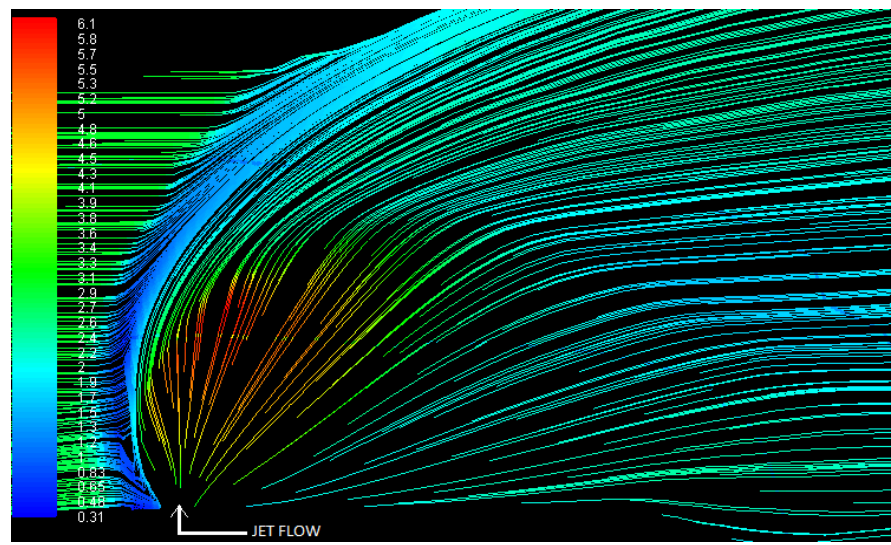

Fig -10(a): Streamlines colored by Mach number for jet-on condition

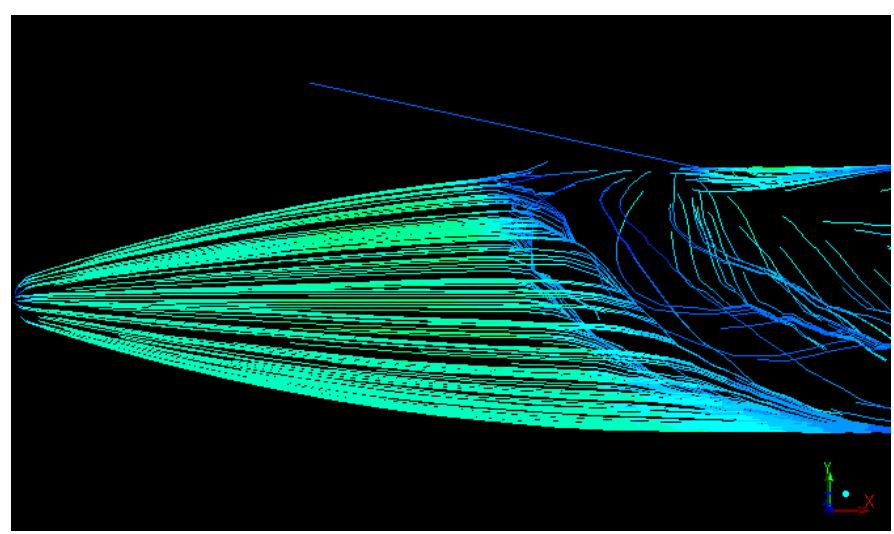

Fig -10(b): Streamlines do not following the shape of the vehicle

The values for aerodynamic coefficients for both jet-off and jet-on cases found from the computational simulation are tabulated in Table 3.

Table-3: Aerodynamic Coefficients Computed By Simulation for JET OFF and JET ON cases

\begin{tabular}{|l|l|l|}
\hline Jet condition & $\mathrm{c}_{\mathrm{d}}$ & $\mathrm{c}_{\mathrm{m}}$ (pitching) \\
\hline OFF & 0.2752 & 0.0005 \\
\hline ON & 0.3020 & 0.0944 \\
\hline
\end{tabular}

\section{CONCLUSIONS}

The interceptor missile model with a lateral jet has been simulated to study the flow-field structure around the body in the presence of external free stream flow. The results obtained from Fluent fabricate a clear picture to understand the concepts and successfully reveals the concealed physics of the present study. It can be concluded from the numerically computed values of aerodynamic coefficients shown by Table 3, that pitching moment coefficient on the body increases from zero to 0.1 approximately.

\section{REFERENCES}

[1]. S.F. Gimelshein, D.A. Levin, and A.A. Alexeenko, "Modelling of Chemically Reacting Flows from Side Jet at High Altitudes", Journal of Spacecraft and Rocket, August 2004
[2]. Cassel, L., A., “Applying jet Interaction Technology”, AIAA Journal of Spacecraft and Rockets, Vol.40, 2003, pp 523-637.

[3]. S.Srinivas Prasad, K.Durga Rao, R.K.Sharma, G.V.Ramana Murty, "Lateral Jet Interaction with the External Flow Field Features on Re-entry Vehicle", International Journal of Engineering and Innovative Technology (IJEIT) Volume 3, Issue 3, September 2013.

[4]. Anderson, J., D., "Fundamentals of Aerodynamics", McGraw and Hill, 2001. 